DOI 10. 18307/2018. 0405

(C) 2018 by Journal of Lake Sciences

\title{
若干水华相关藻类对太湖水体异味物质贡献的初步研究"
}

\author{
李维唯 ${ }^{1}$, 郭康宁 ${ }^{1}$, 刘莉文 ${ }^{1}$,杨 荧 $^{1}$, 李继影 ${ }^{2}$, 徐恒省 ${ }^{2}$, 李建宏 ${ }^{1 * *}$ \\ ( 1 : 南京师范大学生命科学学院, 南京 210023) \\ (2: 苏州市环境监测中心,苏州 215004)
}

\begin{abstract}
摘 要: 太湖水体中鮕味物质 2-甲基异茨醇 (MIB) 和土臭素 ( Geo) 的出现与水华发生在时间上高度重叠,为探寻水华中 常见藻类与嗅味的关系, 本研究通过对实验室培养藻株和野外水样比较分析, 探寻了部分藻株与太湖水体嗅味物质的关 系. 分析实验室培养的 15 株蓝澡 (其中 11 株微囊藻) 、4 株绿藻和 4 株硅藻, 仅硅藻培养物测定出了 Geo, 所有藻株均未检 测出 MIB; 对太湖典型水样分析结果显示, 水体中 MIB 与 $\mathrm{Geo}$ 的浓度与微囊藻细胞浓度无相关性; 实验室模拟微囊藻水华 腐败结果显示, 无论是好氧还是厌氧条件下均未产生 MIB 和 Geo; 这些数据结果说明湖水中 MIB 和 Geo 与水华主要种群 微囊藻无直接关系. 在鱼腥藻水华中测出了高浓度的 MIB, 周年水样分析结果显示鱼腥藻细胞数与 MIB 浓度变化规律一 致, 因此鱼腥藻可能是 MIB 的重要来源. 但实验室培养的 Anabaena sp. PCC7120 无论是在缺氮还是有氮培养条件下均不 产 MIB 和 Geo, 说明嗅味物质的产生具有藻株特异性.
\end{abstract}

关键词: 嗅味物质;蓝藻水华; 微囊藻; 藻类;太湖

\section{Relationship of odor compounds to some algal strains associated with bloom in Lake Taihu}

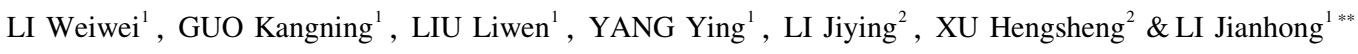

(1: School of Life Sciences, Nanjing Normal University, Nanjing 210023, P.R.China)

(2: Suzhou Environmental Monitoring Centre, Suzhou 215004, P.R.China)

Abstract: Odor compounds 2-methylisocrotene (MIB) and the geosmin ( Geo) were highly overlapped with the water blooms in the Lake Taihu. In this study, the relationship between odor compounds and cyanobacterial or algal strains of blooms in Lake Taihu were investigated by analyzing laboratory cultures and field samples. The cultured strains included 15 cyanobacteria (11 Microcystis strains ), 4 green algae and 4 diatoms. No MIB was detected in all strains, and Geo was only detected in the culture of diatoms. Analysis of field water samples showed that the concentration of Microcystis cells was not correlated with the concentration of MIB and Geo. Decay of Microcysits bloom did not produced MIB and Geo in either aerobic or anaerobic conditions. These data demonstrated that MIB and Geo were not directly related to Microcystis, dominant population of bloom. A high concentration of MIB was found in an Anabaena bloom. Data analysis of annual water samples showed that the cell density of Anabaena was consistent with the change of MIB concentration, which suggested Anabaena should be an important producer of MIB. However, the Anabaena PCC 7120 cultured in laboratory did not produced MIB and Geo both in the culture medium with nitrate or without nitrogen. The result implied that the production of odor substances was of strain specificity.

Keywords: Odor compound; cyanobacterial bloom; Microcystis; algae; Lake Taihu

饮用水中的嗅味问题是公众十分关注的问题, 也是世界上水环境研究的热点问题. 太湖是苏州、无锡等 城市的重要水源地,近十几年来,由于夏季出现严重的微囊藻水华,伴随着总体水质的恶化,水中时常出现

* 国家自然科学基金项目(31370217)、江苏省高校优势学科建设工程(PAPD)和太湖水污染治理专项资金(第八期) 管理类科研课题 (JSzC-G2014-211) 联合资助. 2017-09-25 收稿;2017-11-16 收修改稿. 李维唯 (1993 ), 女, 硕士 研究生;E-mail:li_weiwei0817@163.com.

** 通信作者; E-mail:llijianhong@ njnu.edu.cn. 
土味和腥味等异味, 引起了人们的普遍关注. 藻类是水体中多种嗅味物质的来源之一, 藻类在生长过程中分 泌以及死亡后细胞裂解释放多种具有各种味道的物质,包括水果味、泥土味、鱼腥味和青草味等 ${ }^{[1-2]}$. 2-甲基 异茨醇 (2-methylisoborneol, MIB) 和土臭素 (geosmin, Geo) 是最常见的导致饮用水产生嗅味的 (土味、霝味) 物 质 (嗅觉阈值浓度分别仅为 9 和 $4 \mathrm{ng} / \mathrm{L})^{[3-4]}$, 太湖水体中主要出现的也是这 2 种物质. 以前的研究分析已发 现, 太湖中高浓度 MIB 和 Geo 的出现与微囊藻水华的发生时间高度重叠, 主要出现在 5-9 月 ${ }^{[5-9]}$, 因此, 占 水华生物量 $90 \%$ 以上的微囊藻与 2 种嗅味物质是否存在因果关系为人们所关注. 已报道的大部分研究认为 微囊藻并不在产 MIB 和 Geo 的蓝藻之列 ${ }^{[10-11]}$, 但也有研究显示 ${ }^{[12]}$ 在微囊藻培养物中测得较高浓度的 MIB. 由于蓝藻的次生代谢具有复杂的多样性, 有必要进一步通过本土藻株的研究确认微囊藻与这些嗅味物质的 关系. 同时, 水华发生过程伴随着部分藻体死亡, 也有必要弄清微囊藻藻体腐败过程是否会是这些嗅味物质 的直接来源. 另一方面, 除了微囊藻外, 水华中也含有鱼腥藻等其他蓝藻种类, 同时还伴生有少量绿藻和硅 藻,这些藻类对太湖水体的嗅味有怎样的贡献都是有待弄清的问题.

国内外已有很多关于湖泊河流水体中异味物质与藻类相关性的研究报道, 但很多报道是基于野外调查 的数据, 分析异味物质与藻之间的关系. 由于自然生态系统的复杂性, 这些调查结果难以确认产生异味物质 的藻类. 通过分析实验室纯培养的藻株, 可以确定它们产异味物质的特性, 然而, 由于自然水体中绝大部分 种类是难以分离培养的, 不同水体中藻类的生理状态 (生态类型) 也存在一定的差异, 所以虽然已有不少研 究确定了一些藻株产嗅味物质的特性 ${ }^{[10-11]}$, 但对于不同地域的水体, 还必须通过分析土著藻株, 才能得出较 准确的结论. 本文从太湖和邻近水体中分离培养了一些水华常见种类, 测定了实验室纯藻株培养物产嗅味 物质的特性, 并结合天然水华样品的分析, 讨论了太湖主要嗅味物质 MIB 和 Geo 的来源, 旨在为饮用水水质 的管理提供科学依据.

\section{1 实验材料及方法}

\section{1 实验藻株}

为探明水华相关的常见藻类产嗅味物质的特点, 本实验以太湖、南京小水体中分离的微囊藻为主, 结合 模式藻株, 选择了夏季水体中常见的蓝藻门、绿藻门和硅藻门的代表性种类为材料, 用于分析各门类产嗅味 物质的特点. 本研究所用的藻株及来源见表 1 .

\section{2 藻类培养}

除了硅藻采用硅藻培养基 $\mathrm{DM}^{[13]}$ 以外其余藻类均采用 $\mathrm{BG}-11$ 培养基培养. 藻类在 $28^{\circ} \mathrm{C}$ 、白色日光灯 3000 lux 连续光照下静置培养, 每天间隙摇动数次.

藻类培养至对数生长期 (接种培养 $8 \sim 10 \mathrm{~d}, \mathrm{OD}_{700}$ 为 $0.5 \sim 0.8$ ), 藻液每 $10 \mathrm{ml}$ 加 $1 \mathrm{ml} 3 \mathrm{~g} / \mathrm{L}$ 的 $\mathrm{CuSO}_{4}$ 溶液 保存,采用已灭菌的 $0.45 \mu \mathrm{mol} / \mathrm{L}$ 醋酸纤维滤膜过滤去除细胞后测定水样的嗅味物质.

\section{3 微囊藻水华腐败实验}

捞取太湖水体表层含浓稠微囊藻水华的水样用于腐败实验. 好氧腐败处理: 取微囊藻水华样品 $50 \mathrm{ml}$ 放 人灭菌的 $250 \mathrm{ml}$ 锥形瓶中, 置于光照摇床 150 转 $/ \mathrm{min}$ 摇动培养, 光照强度 $500 \mathrm{lux}$, 温度 $30^{\circ} \mathrm{C}$; 厌氧腐败处 理: 取 $100 \mathrm{ml}$ 蓝藻水华样品, 置于灭菌的大试管中, 用塑料膜包裹封口, 置于 $30^{\circ} \mathrm{C}$ 下处理; 上述处理持续 $10 \mathrm{~d}$ 后离心取上清液测定嗅味物质.

\section{4 嗅味物质测定}

采用顶空固相微萃取、气一质联用的方法进行定性定量测定 ${ }^{[14]}$. 主要测定 4 种藻类产生的常见嗅味物 质:2-甲基异茨醇 (MIB)、土臭素 ( Geo)、 $\beta$-柠檬环醛 ( Cyc) 和 $\beta$-紫罗兰酮 ( Ion).

顶空固相微萃取: 取 $10 \mathrm{ml}$ 水样置于 $20 \mathrm{ml}$ 的广口瓶中, 加人 $3 \mathrm{~g}$ 烘好后的氯化钠, 在 $60^{\circ} \mathrm{C}$ 下预平衡 5 $\min$ 后, 萃取 $30 \mathrm{~min}$. 在 $250^{\circ} \mathrm{C}$ 下热解析 $3 \mathrm{~min}$ 后进样.

气相色谱: DB- $5 \mathrm{~ms}(30 \mathrm{~m} \times 0.25 \mathrm{~mm} \times 0.25 \mu \mathrm{m})$ 色谱柱, 载气为氦气, 恒流模式, 流量 $1.0 \mathrm{ml} / \mathrm{min}$. 柱温: $50^{\circ} \mathrm{C}$ 保持 $2 \mathrm{~min}$, 以 $8^{\circ} \mathrm{C} / \mathrm{min}$ 升至 $160^{\circ} \mathrm{C}$, 再以 $20^{\circ} \mathrm{C} / \mathrm{min}$ 升至 $280^{\circ} \mathrm{C}$ 保持 $3 \mathrm{~min}$. 进样口温度 $250^{\circ} \mathrm{C}$, 质谱接口 温度 $250^{\circ} \mathrm{C}$. 不分流进样, 进样时间 $3 \mathrm{~min}$.

质谱: EI 离子源, 能量 $70 \mathrm{eV}$, 温度 $230^{\circ} \mathrm{C}$; 四级杆温度 $150^{\circ} \mathrm{C} ; 2,4,6$-TCA-D5 内标物质的保留时间是 1 
$\min$, 定量离子是 215.

表 1 实验用藻株

Tab.1 Strain list in the experiment

\begin{tabular}{|c|c|c|c|}
\hline 门类 & 属 & 藻株 & 藻株来源 \\
\hline \multirow[t]{15}{*}{ 蓝藻门 } & 微囊藻属 Microcystis & Wo & 太湖 (群体状态) \\
\hline & 微囊藻属 Microcystis & W1 & 太湖 (群体状态) \\
\hline & 微囊藻属 Microcystis & W2 & 太湖 (群体状态) \\
\hline & 微囊藻属 Microcystis & W3 & 太湖 (群体状态) \\
\hline & 微囊藻属 Microcystis & W4 & 太湖 (群体状态) \\
\hline & 微囊藻属 Microcystis & L1 & 栖霞山小水体(群体状态) \\
\hline & 微囊藻属 Microcystis & $\mathrm{L} 2$ & 牛首山小水体(群体状态) \\
\hline & 微囊藻属 Microcystis & L3 & 紫金山小水体(群体状态) \\
\hline & 微囊藻属 Microcystis & XW01 & 玄武湖(群体状态) \\
\hline & 微囊藻属 Microcystis & PCC7806 & 法国巴斯德研究所 (单细胞) \\
\hline & 微囊藻属 Microcystis & FACHB315 & 武汉水生所(单细胞) \\
\hline & 鱼腥藻属 Anabaena & PCC7120 & 法国巴斯德研究所 \\
\hline & 鱼腥藻属 Anabaena & DY & 太湖冬季水华(非培养物） \\
\hline & 集胞藻属 Synechocystis & PCC6803 & 法国巴斯德研究所 \\
\hline & 浮丝藻 Planktothrix & $\mathrm{SP}$ & 南京中山陵小水体 \\
\hline \multirow[t]{4}{*}{ 绿藻门 } & 栅列藻属 Scenedesmus & G1 & 南京仙林小水体 \\
\hline & 栅列藻属 Scenedesmus & G2 & 太湖 \\
\hline & 小球藻属 Chlorella & G3 & 太湖 \\
\hline & 衣藻属 Chlamydomonas & G4 & 南京仙林小水体 \\
\hline \multirow[t]{4}{*}{ 硅藻门 } & 舟形藻属 Navicula & Sil & 南京仙林小水体 \\
\hline & 脆杆藻属 Fragilaria & $\mathrm{Si} 2$ & 南京仙林小水体 \\
\hline & 脆杆藻属 Fragilaria & $\mathrm{Si} 3$ & 太湖 \\
\hline & 脆杆藻属 Fragilaria & $\mathrm{Si} 4$ & 太湖 \\
\hline
\end{tabular}

表 2 几株微囊藻产生的嗅味物质 $(\mathrm{ng} / \mathrm{L})$

Tab.2 Odor compounds produced by Microcystis strains

\begin{tabular}{ccccc}
\hline \multirow{2}{*}{ 微囊藻藻株 } & \multicolumn{4}{c}{ 嗅味物质 } \\
\cline { 2 - 5 } & Cyc & Ion & MIB & Geo \\
\hline W0 & 1855 & 3222 & ND & ND \\
W1 & 6041 & 1458 & ND & ND \\
W2 & 3458 & 2284 & ND & ND \\
W3 & 187 & 259 & ND & ND \\
W4 & 971 & 1264 & ND & ND \\
L1 & 11531 & 2784 & ND & ND \\
L2 & 10689 & 1738 & ND & ND \\
L3 & 2864 & 1894 & ND & ND \\
FACHB315 & 803 & 7.6 & ND & ND \\
\hline
\end{tabular}

$\mathrm{ND}$ 表示低于检测限, 未检出.

\section{2 结果分析}

\section{1 不同门类藻产生的嗅味物质}

对分离纯化培养的 14 株水华发生期间常见的藻类进 行异味物质分析, 结果如图 1 所示. 包括微囊藻在内的 8 个蓝藻藻株仅检测出 Cyc 和 Ion; 4 株绿藻仅产生极少量 的嗅味物质; 4 株硅藻培养物中检出不同浓度的 Geo, 最高 浓度达 $109 \mathrm{ng} / \mathrm{L}$. 然而在所有的藻株中均却未检出 MIB.

为进一步确认太湖蓝藻水华主要种类一一微囊藻产嗅 味物质的特性, 又对分离自太湖的 5 株微囊藻 (W0 W 4 ) 和 一株源于中国科学院水生生物研究所淡水藻种库的微囊藻 FACHB315 进行分析, 与上述结果相同 (表 2, 其中的 L1 L3 为图 1 中藻株的重复实验), 所有这些本土微囊藻藻株均不 产生 MIB 和 Geo, 仅仅产生 Cyc 和 Ion, 这与文献已报道的 研究结果一致 ${ }^{[15-16]}$. 但 Cyc 和 Ion 是具有高嗅觉阈值的芳 香味物质,并不是导致太湖水体嗅味的主要物质.

\section{2 天然水样中微囊藻密度与嗅味物质浓度的相关性}

为进一步探寻太湖水体中 MIB 和 Geo 与微囊藻水华的关系, 2015 年夏季对出现显著嗅味的某取水口进 


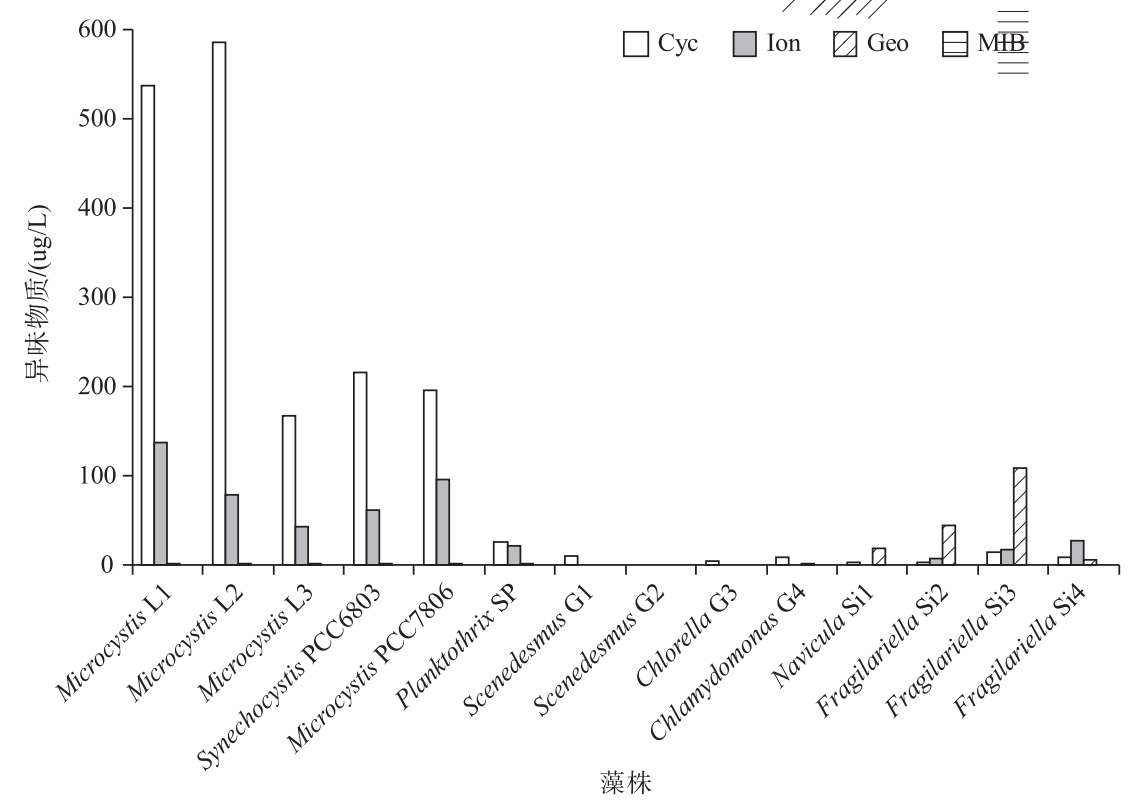

图 1 不同藻株产嗅味物质的特性

Fig.1 Odor compounds produced by algal strains

行了采样, 相距约 $500 \sim 1000 \mathrm{~m}$ 的 3 个采样点分别为 $\operatorname{SSC} 1\left(31^{\circ} 18^{\prime} 37^{\prime \prime} \mathrm{N}, 120^{\circ} 16^{\prime} 19^{\prime \prime} \mathrm{E}\right) 、 \operatorname{SSC} 2\left(31^{\circ} 18^{\prime} 28^{\prime \prime} \mathrm{N}\right.$, $\left.120^{\circ} 15^{\prime} 43^{\prime \prime} \mathrm{E}\right)$ 和 $\operatorname{SSCN}\left(31^{\circ} 17^{\prime} 14^{\prime \prime} \mathrm{N}, 120^{\circ} 16^{\prime} 19^{\prime \prime} \mathrm{E}\right)$. 采样时水面可见显著漂浮的微囊藻水华, 样点的基本水质 参数和微囊藻细胞密度见表 3. 测定结果表明, 3 个样点水体中存在较高浓度的 MIB 和 Geo(图 2). 比较 SSC1 和 SSC2 水样, 二者的藻密度和其他水质参数基本相同, 但 MIB 浓度却相差甚远, 取水口南侧样点 $(\mathrm{SSCN})$ 的微囊藻细胞密度明显低于 SSC1 和 SSC2 点位, 但 MIB 浓度却显著高于 SSC2 水样 (图 2). 由此可 见水体中 MIB 浓度与微囊藻细胞密度并无直接关系. 对 Geo 的测定也呈现出类似的结果 (图 $2 \mathrm{~b}$ ), 其浓度与 藻密度未见相关性. 这些数据与上述实验室培养物的测定结果吻合, 显示了微囊藻与太湖水体中 MIB 和 Geo 的出现不存在直接的相关性.

已有的调查数据显示 ${ }^{[17]}$, 高浓度 MIB 的出现虽然总体上与微囊藻水华的发生存在时间上的吻合 (5-9 月 ), 但二者的浓度变化并不完全一致:一方面在 7 月的水华高峰期 MIB 出现一个显著的浓度低谷,使水体 中 MIB 浓度曲线呈明显的 M 型; 另一方面仅到了 9 月底, MIB 浓度就迅速降低到了很低的水平, 而此时微囊 藻水华依然处在较高浓度. 这些现象均表明了微囊藻与太湖水体的嗅味物质没有直接关系.

表 3 几个采样点的微囊藻细胞密度和水质参数

Tab.3 Microcystis concentration and water quality in sampling sites

\begin{tabular}{cccccc}
\hline 采样点 & 水温 $/{ }^{\circ} \mathrm{C}$ & $\mathrm{pH}$ & 浊度 $/ \mathrm{NTU}$ & 溶解氧 $/(\mathrm{mg} / \mathrm{L})$ & 微囊藻细胞密度 $/\left(\times 10^{4}\right.$ cells $\left./ \mathrm{L}\right)$ \\
\hline $\mathrm{SSC} 1$ & 24.66 & 8.93 & 49 & 9.35 & 4800 \\
$\mathrm{SSC} 2$ & 24.66 & 8.93 & 49 & 9.35 & 4800 \\
$\mathrm{SSCN}$ & 24.37 & 8.92 & 69 & 9.37 & 3800 \\
\hline
\end{tabular}

\section{3 水华腐败过程对嗅味物质的影响}

水华发生期间通常伴随一定量微囊藻细胞的死亡, 死亡裂解的藻细胞会为附生的微生物提供营养, 从 而产生嗅味物质. 为了分析水华在自然腐败过程中是否会产生 MIB 和 $\mathrm{Geo}$, 以天然水华样品为材料, 在实验 室内模拟了水华腐败的过程. 腐败过程模拟设置了好氧 (有光) 和厌氧(黑暗) 2 种腐败环境. 结果表明,无论 是好氧还是戻氧条件下, 腐败一段时间后 2 种嗅味物质浓度都显著降低,特别是在好氧环境条件下, 2 种嗅 

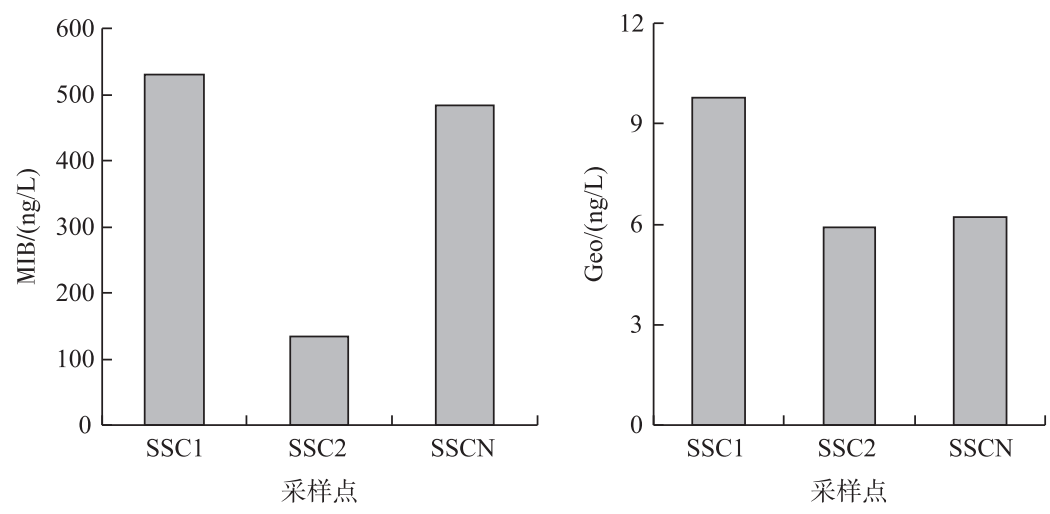

图 2 太湖水样中的 MIB 和 Geo 浓度

Fig.2 MIB and Geo concentrations in water samples of Lake Taihu

味物质的浓度几乎降至 0 (图 3). 这一结果显示, 微囊藻水华腐败的过程, 并不会直接产生 MIB 和 Geo, 相反 一些微生物的生长, 特别是好养菌的代谢会分解这些嗅味物质.
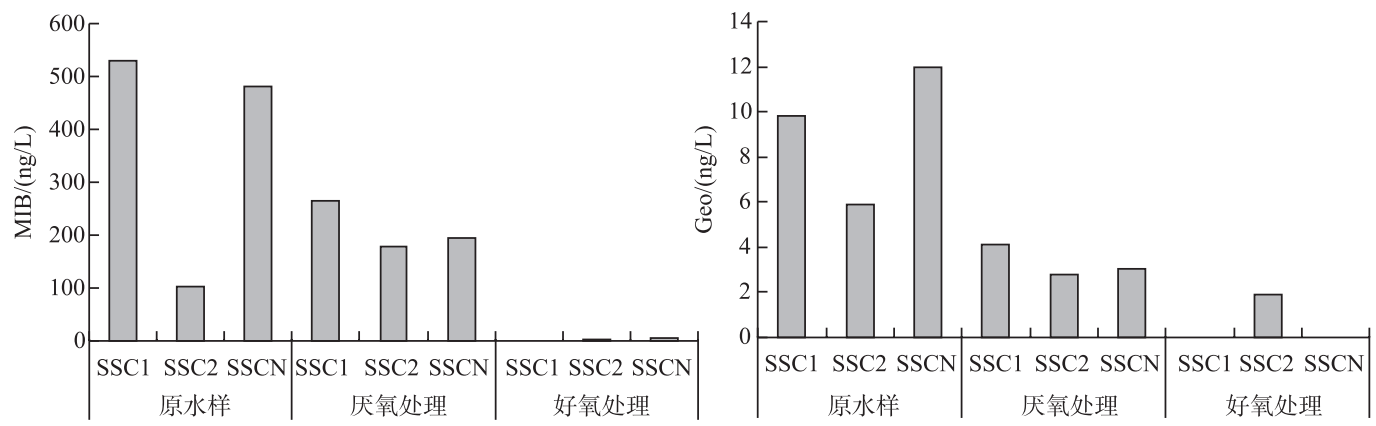

图 3 水华腐败前、后 MIB 和 Geo 的浓度变化

Fig.3 MIB and Geo concentrations before and after bloom decay

表 4 冬季鱼腥藻水华水样的嗅味物质 $(\mathrm{ng} / \mathrm{L})$

Tab.4 Odor compounds of Anabaena bloom in winter

\begin{tabular}{ccccc}
\hline 编号 & MIB & Cyc & Geo & Ion \\
\hline DY1 & 886 & 7387 & ND & 1606 \\
DY2 & 2626 & 4793 & ND & 348 \\
DY3 & 1480 & 11236 & ND & 943 \\
平均值 & 1664 & 7805 & ND & 966 \\
\hline
\end{tabular}

ND 表示低于检测限, 未检出.

\section{4 鱼腥藻对 MIB 的贡献}

鱼腥藻是太湖中常见的种类, 2015 年 12 月末无 锡等地的局部水域出现了鱼腥藻水华, 对水华区域 的 3 个样品 DY1、DY2 和 DY3 (样点相距约 $50 \mathrm{~m}$ ) 的 分析结果显示, MIB 浓度最高达到了 $2626 \mathrm{ng} / \mathrm{L}$ (表 4). 对这一水样中的鱼腥藻用太湖原水在实验室内 维持培养了 6 个月 (无法分离培养, 在维持培养过程 中藻逐渐死亡), 测得的培养液中 MIB 浓度始终维持 在 $1000 \mathrm{ng} / \mathrm{L}$ 以上 (数据未列出). 由于有氧条件下

MIB 可被水样中许多细菌分解, 长期维持培养的样品中一直存在如此高浓度的 MIB, 理应是藻不断产生的结 果. 因此,鱼腥藻可能对太湖水体中的 MIB 有一定的贡献.

夏季太湖水华发生期间, 鱼腥藻属也是常见的伴生种类. 根据 2014 年 8 月至 2015 年 8 月太湖某典型样 点 MIB 浓度与鱼腥藻细胞密度变化统计结果显示, 鱼腥藻属细胞密度与 MIB 浓度的变化趋势相似(图 4), 这一现象也提示, 鱼腥藻可能是太湖水体 MIB 的重要来源. Izaguirre 等 ${ }^{[10]}$ 研究指出, 鱼腥藻是 MIB 和 Geo 的 典型生产者, Wang 等 ${ }^{[18]}$ 也从乌克兰鱼腥藻 (Anabaena ucrainica) 中分析鉴定出了 Geo 合成基因, 但在本研究 测定的样品中却并未发现鱼腥藻产生 Geo. 这一结果也显示了不同地域的藻类产嗅味物质的特性有较大的 
差异.

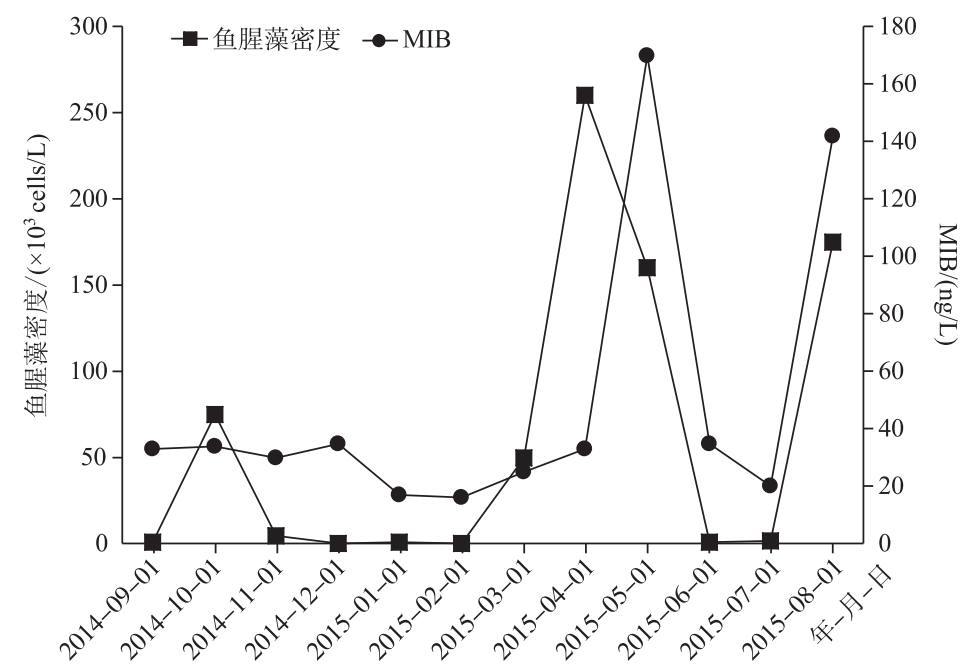

图 4 太湖某取水口鱼腥藻密度与 MIB 浓度的周年变化

Fig.4 Annual variation of cell density of Anabaena and MIB concentration of a water intake in Lake Taihu

为进一步验证鱼腥藻产 MIB 的能力, 需对纯培养鱼腥藻进行产嗅味物质研究, 但由于未能成功分离培 养太湖的鱼腥藻藻株, 故以模式藻株 Anabaena sp. PCC7120 为材料进行了实验. 然而实验的结果显示, 不论 是新鲜培养物 (指数生长期) 还是久置的培养物 (稳定期), 也不论是有氮培养还是无氮培养, 所有条件下均 未测定出 MIB 和 Geo(数据未列出), 与 Suurnäkki 等 ${ }^{[19]}$ 对两株鱼腥藻的研究结果一致. 这些结果显示: 嗅味 物质的产生不仅仅有属种的特异性,更具有藻株的差异.

\section{3 讨论}

\section{1 微囊藻与嗅味物质的关系}

藻类与饮用水中嗅味物质的关系, 是国内外广泛关注的问题, 已有研究表明, 各个门类的藻类可能会产 生不同的嗅味物质, 水体中的 MIB 和 Geo 主要源于蓝藻和放线菌 ${ }^{[20]}$, 束丝藻 (Aphanizomenon)、浮丝藻 (Planktothrix)、伪鱼腥藻 (Pseudanabaena) 和聚球藻 (Synechococcus) 属等都可产生 MIB 和 Geo, 而微囊藻属并 不产生这 2 种物质 ${ }^{[21]}$. 但可能是由于大部分野外藻株难以分离的缘故, 对同一个属不同种类开展的篮查研 究相对较少. 微囊藻属是导致蓝藻水华的重要种类, 从产生微囊藻毒素 (MCs) 的能力来看, 不同的藻株产生 MCs 种类和产量有很大的差异. 由此可见, 作为原核生物的蓝藻, 在次生代谢产物上具有复杂的多样性. 虽 然过往的文献报道中, 微囊藻属并不在产 MIB 和 Geo 的蓝藻之列, 但 Zhang 等 ${ }^{[22]}$ 在一株铜绿微囊藻的培养 物质中测定出了 MIB 和 Geo. 虽然作者将微囊藻衰亡期的 MIB 和 Geo 浓度增加归结为伴生的放线菌产生, 但对新鲜培养物中浓度高达 $308 \mathrm{ng} / \mathrm{L}$ 的 MIB 来源并没有给出合理的解释. 本研究通过 11 株微囊藻培养物 和野外水华样品测定的数据分析, 进一步验证了太湖水体中的 MIB 与 Geo 并非微囊藻代谢产生; 另一方面, 天然微囊藻水华的腐败无论是在好氧还是厌氧条件下, MIB 和 Geo 浓度均显著降低, 这一结果说明, 微囊藻 附生菌中可产 MIB 的放线菌并不能直接以腐败藻为 “培养基”, 大量生长繁殖合成 MIB 和 Geo, 这一数据结 果也不同于 Zhang 等 ${ }^{[22]}$ 的结果. 上述这些研究结果表明, 微囊藻与水体中的 MIB 和 Geo 没有直接的关联. 微囊藻水华中虽然有较高浓度的 Cyc 和 Ion, 但 Cyc 和 Ion 是两种嗅味阈值较高、带芳香味的物质, 测得的结 果大多并未达到嗅味阈值浓度,因此通常并不会导致异味.

除了藻类外, 水体中许多异养微生物也是 MIB 和 Geo 的来源 ${ }^{[1]}$, 虽然在本文的实验中微囊藻水华样品 中的细菌 (包括微囊藻附生菌和周际水体中的细菌) 并未产生 MIB 和 Geo, 但在天然水体中通常都具有非常 丰富的产嗅味物质微生物类群, 蓝藻水华的细胞死亡、裂解可为这些异养微生物提供丰富的有机物营养, 为 
它们的大量繁殖和嗅味物质的合成提供物质基础. 因此, 微囊藻水华虽然不是 MIB 和 Geo 的直接生产者, 但 依然可能是水华发生期间水体嗅味物质浓度较高的重要原因之一.

\section{2 硅藻培养物中测定出 Geo 的分析}

很多调查发现,一些湖泊和河流中硅藻与 MIB/Geo 浓度存在明显的相关性, 但硅藻是否直接产 Geo 似 乎是一个尚无定论的问题. Olsen 等 ${ }^{[23]}$ 指出, 目前关于硅藻 (无菌藻株) 与异味物质关系的研究仅有 Sugiura

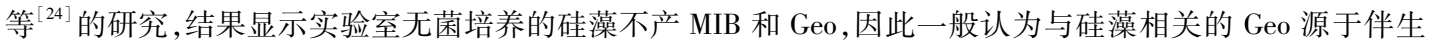
的放线菌. 但这一研究似乎并不能说明所有的硅藻都不产生 Geo.

Juttner ${ }^{[25]}$ 对采集的底栖硅藻进行了细胞内容物的测定, 测得其 Geo 浓度相对较高; Schafran ${ }^{[26]}$ 在 AWWA Water Quality and Research Committee 2016 年 3 月的报告中指出, 产生 MIB 和 Geo 的硅藻包括星杆藻 (Asterionella) 和小环藻 (Cyclotella). 李继影等 ${ }^{[17]}$ 对太湖某饮用水源的数据分析显示, 2013 年全年 MIB 和 Geo 浓度均与硅藻浓度呈高度正相关. 因此, 硅藻是否产 MIB 和 Geo 有待更多的研究去证实.

本研究中采用的硅藻藻株虽然是纯培养藻种, 但无法排除存在附生的产 Geo 放线菌, 因此硅藻培养物 中的 Geo 不能排除是附生放线菌的产物. 即便如此, 本文的测定结果依然可以说明: 硅藻与 Geo 的出现密切 相关.

\section{3 鱼腥藻产 MIB 的分析}

Qi 等 ${ }^{[27]}$ 对全太湖的调查分析显示颤藻 (Oscillatoria) 可能是 MIB 的来源, 但对于水华发生水域, 鱼腥藻 的生物量更大, 在太湖某些区域往往和微囊藻同为水华的重要组成 ${ }^{[28]}$. 因此鱼腥藻对水华发生区域高浓度 MIB 的出现应该有更大的贡献. 刘洋 ${ }^{[29]}$ 采用分子标记的方法对 2009-2010 年太湖水样中水华鱼腥藻时空 分布进行了分析, 结果显示在不同湖区都普遍存在丰富的鱼腥藻, 密度最高值达 $4 \times 10^{7}$ cells/L. 近年来由于 加强了对太湖污染的治理, 部分水域总氮水平显著降低, 具有固氮能力的鱼腥藻密度有显著增加的趋势, 部 分水域甚至发生鱼腥藻水华, 因此, 鱼腥藻产异味物质对饮用水源的影响更应值得关注.

\section{4 产嗅味物质藻株的特异性}

从已报道的文献来看 ${ }^{[11,19,26]}$, 不同藻株嗅味物质产生的能力是完全不同的, 无法通过简单的藻种鉴定 来确定其是否产嗅味物质. 仅以鱼腥藻为例来看, 文献的报道有的藻株只产 MIB, 有的藻株只产 Geo, 有的藻 株两种都产生, 也有藻株两种都不产生 (如本研究中测定的藻株 PCC7120). 因此必须通过纯化培养, 结合产 异味物质基因的分析进行确认 ${ }^{[18-19]}$. 然而由于自然界中大部分藻株的分离培养都很困难, 特别是要排除附 生菌的干扰,需采用无菌藻株进行分析. 因此,要完全弄清藻类与嗅味物质的关系还需要大量的研究.

对于放线菌和粘细菌合成 MIB 和 Geo 的代谢途径目前已有了较深人的研究, 基于这些代谢途径的分 析, 在蓝藻中也可以通过基因分析推测一些种类产嗅味物质的可能性 ${ }^{[30]}$, 但是由于萜类物质在不同生物体 中的代谢途径会有很大的差异, 目前对蓝藻和其他物种的 MIB 和 Geo 合成代谢途径, 以及这些代谢的调控 机制所知甚少, 有待进一步的研究发掘. 关于藻类对太湖嗅味物质的贡献也有待更多的研究去补充完善. 致谢: 2015 年冬季鱼腥澡水华样品由无锡市环境检测中心张军毅博士采集提供, 在此表示感谢.

\section{4 参考文献}

[ 1 ] Knappe D, Viswakumar A. Development of an analytical method for taste and odor compounds commonly found in drinking water sources. Water Resources Research Institute of the University of North Carolina, 2011.

[ 2 ] Jin CX, Zhang JW, Wang R et al. Research progress of smell and taste reason in drinking water. Environment and Develop$m e n t, 2010,22(2): 83-87$. [靳朝喜, 张军伟, 王锐等. 饮用水中致嗅和味原因研究进展. 环境与发展, 2010, 22 (2) : 83-87.]

[ 3 ] Watson SB. Cyanobacterial and eukaryotic algal odour compounds: signals or by-products? A review of their biological activity. Phycologia, 2003, 42(4) : 332-350.

[ 4 ] Watson SB. Aquatic taste and odor: A primary signal of drinking-water integrity. Journal of Toxicology \& Environmental Health Part A, 2004, 67(20/21/22) : 1779-1795.

[ 5 ] Jin X. Research on the typical odor substances and their changes in algae metabolism products [Dissertation]. Nanjing: Nanjing University of Science and Technology, 2009. [ 金星. 藻类代谢产物中典型异味物质及其变化规律研究 [学位 
论文]. 南京: 南京理工大学, 2009.]

[ 6 ] Zhang JF. Study on the monitoring of odor substances and its changes in the water of Taihu Lake[Dissertation]. Nanjing: Nanjing University of Science and Technology, 2010. [张建芳. 太湖原水中异味物质的监测及其变化规律研究 [学位 论文]. 南京: 南京理工大学, 2010.]

[ 7 ] Qin HB, Zhang XY, Fan L et al. Off-flavor compounds in drinking water sources of Taihu in Suzhou and their correlationswith environmental factors. Environmental Monitoring and Forewarning, 2016, 8(3): 38-42. [秦宏兵, 张晓斊, 范苓 等. 苏州市太湖饮用水源地异味物质种类及其与环境因子相关性分析. 环境监控与预警，2016，8(3): 38-42.]

[ 8 ] Xu ZQ, Zhang XY, Liao L et al. Study on the detection of the main odor substances and the temporal and spatial variation of the drinking water source in Taihu. Anhui Agricultural Science Bulletin, 2016, 22(15): 73-74. [徐振秋, 张晓望, 廖 蕾等. 太湖饮用水源地主要异味物质检测及其时空变化规律研究. 安徽农学通报, 2016, 22(15): 73-74.]

[ 9 ] Xu ZQ, Zhang XY, Liao L et al. Study the time relationship with the main odor source water in Taihu. Guangdong Chemistry, 2016, 43(17) : 162-163. [徐振秋, 张晓望, 廖蕾等. 太湖饮用水源地主要异味物质时间变化规律研究. 广东 化工, 2016, 43(17): 162-163.]

[10] Izaguirre G, Taylor WD. A guide to geosmin- and MIB-producing cyanobacteria in the United States. Water Science \& Technology, 2004, 49(9): 19-24.

[11] Sugiura N, Utsumi M, Wei B et al. Assessment for the complicated occurrence of nuisance odours from phytoplankton and environmental factors in a eutrophic lake. Lakes \& Reservoirs: Research and Management, 2004, 9: 195-201.

[12] Zhang K, Lin TF, Zhang T et al. Characterization of typical taste and odor compounds formed by Microcystis aeruginosa. Journal of Environmental Sciences, 2013, 25(8) : 1539-1548.

[13] Andersen RA ed. Diatom medium, modified. London: Elsevier Academic Press, 2005: 481.

[14] Fan L, Qin HB, Zhang XY. Determination of nine off-flavor compounds in water by gas chromatography-mass spectrometry with head space solid phase micro-extraction. Journal of Jiangnan University: Natural Science Edition, 2014, 13(3): 355-359. [范苓, 秦宏兵, 张晓忞. 顶空固相微萃取-气相色谱/质谱法同时测定富营养化水体中 9 种异味物质. 江 南大学学报: 自然科学版, 2014, 13(3): 355-359.]

[15] Watson SB, Ridal J, Boyer G. Taste and odour and cyanobacterial toxins: impairment, prediction, and management in the Great Lakes. Canadian Journal of Fisheries and Aquatic Sciences, 2008, 65(8) : 1779-1796.

[16] Xi Y, Xie P, Yu Y et al. Microcystis aeruginosa/Pseudomonas pseudoalcaligenes interaction effects on off-flavors in algae/ bacteria co-culture system under different temperatures. Journal of Environmental Sciences, 2015, 31(5) : 38-43.

[17] Li JY, Zhang XY, Xu HS et al. Preliminary study on variation and source of main odor compounds in taihu drinking water source. Administration and Technique of Environmental Monitoring, 2016, 28(3): 69-71. [李继影, 张晓赞, 徐恒省等. 太湖水源水主要异昧物质变化规律及来源初探. 环境监测管理与技术, 2016, 28(3): 69-71.]

[18] Wang Z, Shao JH, Xu Y et al. Genetic basis for geosmin production by the water bloom-forming cyanobacterium, Anabaena ucrainica. Water, 2015, 7: 175-187.

[19] Suurnäkki S, Gomez-Saez GV, Rantala-Ylinen A et al. Identification of geosmin and 2-methylisoborneol in cyanobacteria and molecular detection methods for the producers of these compounds. Water Research, 2015, 68: 56-66.

[20] Peter A. Taste and odor in drinking water: sources and mitigation strategies[Dissertation]. Switzerland: Swiss Federal Institute of Technology Zurich, 2008.

[21] Graham JL, Loftin KA, Ziegler AC et al. Cyanobacteria in lakes and reservoirs: Toxin and taste-and-odor sampling guidelines. Geological Survey Techniques of Water-Resources Investigations, 2008.

[22] Zhang K, Lin TF, Zhang T et al. Characterization of typical taste and odor compounds formed by Microcystis aeruginosa. Journal of Environmental Sciences, 2013, 25(8) : 1539-1548.

[23] Olsen BK, Chislock MF, Wilson AE. Eutrophication mediates a common off-flavor compound, 2-methylisoborneol, in a drinking water reservoir. Water Research, 2016, 92 : 228-234.

[24] Sugiura N, Inamori Y, Hosaka Y et al. Algae enhancing musty odor production by actinomycetes in Lake Kasumigaura. Hydrobiologia, 1994, 288(1) : 57-64.

[25] Jüttner F. Evidence that polyunsaturated aldehydes of diatoms are repellents for pelagic crustacean grazers. Aquatic Ecology, 2005, 392: 271-282.

[26] Schafran GC. Controlling algae-related tastes and odors: From source to tap. VA AWWA Water Quality and Research Com- 
mittee Seminar, March 23, 2016.

[27] Qi M, Chen J, Sun X et al. Development of models for predicting the predominant taste and odor compounds in Taihu lake, China. PLos One, 2012, 7(12): e51976.

[28] Zhang JY, Zhu BC. The study on the species and succession of cyanobacteria in Taihu Lake (Wuli Lake). Nanning: Proceedings of academic annual meeting of Chinese Society For Environmental Sciences, 2012: 1495-1499. [张军毅, 朱冰 川. 太湖 (五里湖) 蓝藻水华种类及其演替规律研究. 南宁: 中国环境科学学会学术年会, 2012: 1495-1499.]

[29] Liu Y. Studies on the diversity, spatial-temporal distribution, and physiological characters of Anabaena flos-aquae in Taihu Lake[Dissertation]. Wuhan: University of Chinese Academy of Sciences, 2013. [刘洋. 太湖水华鱼腥藻的多样性、时 空分布及生理特性研究[学位论文]. 武汉: 中国科学院大学, 2013.]

[30] Zhang T, Li DL, Li J. Biosynthesis of geosmin and 2-methylisoborneol in the prokaryotes-A review. Acta Microbiologica Sinica, 2012, 52 (2) : 152-159. [张婷, 李德亮, 李杰. 原核生物中土霉味化合物二甲萘烷醇和 2-甲基异茨醇生物 合成研究进展. 微生物学报, 2012, 52(2): 152-159.] 